\title{
Zygosaccharomyces rouxii Combats Salt Stress by Maintaining Cell Membrane Structure and Functionality
}

\author{
Dingkang Wang ${ }^{1,2}$, Min Zhang ${ }^{1,2}$, Jun Huang ${ }^{1,2}$, Rongqing Zhou ${ }^{1,2}$, Yao Jin ${ }^{1,2 *}$, and Chongde $\mathrm{Wu}^{1,2 *}$ \\ ${ }^{1}$ College of Light Industry, Textile and Food Engineering, Sichuan University, Chengdu 610065, P.R. China \\ ${ }^{2}$ Key Laboratory of Leather Chemistry and Engineering, Ministry of Education, Sichuan University, Chengdu 610065, P.R. China
}

\author{
Received: April 3, 2019 \\ Revised: August 22, 2019 \\ Accepted: October 11, 2019 \\ First published online: \\ October 13, 2019 \\ ${ }^{*}$ Corresponding authors \\ Y.J. \\ Phone: +86-13882197633 \\ Fax: +86-28-85405237 \\ E-mail: Yaojin12@scu.edu.cn \\ C.W. \\ Phone: +86-28-85406149 \\ Fax: +86-28-85405237 \\ E-mail: cdwu@scu.edu.cn \\ pISSN 1017-7825, eISSN 1738-8872 \\ Copyright(C 2020 by \\ The Korean Society for Microbiology \\ and Biotechnology
}

Zygosaccharomyces rouxii is an important yeast that is required in the food fermentation process due to its high salt tolerance. In this study, the responses and resistance strategies of $Z$. rouxii against salt stress were investigated by performing physiological analysis at membrane level. The results showed that under salt stress, cell integrity was destroyed, and the cell wall was ruptured, which was accompanied by intracellular substance spillover. With an increase of salt concentrations, intracellular $\mathrm{Na}^{+}$content increased slightly, whereas intracellular $\mathrm{K}^{+}$ content decreased significantly, which caused the increase of the intracellular $\mathrm{Na}^{+} / \mathrm{K}^{+}$ratio. In addition, in response to salt stress, the activity of $\mathrm{Na}^{+} / \mathrm{K}^{+}$-ATPase increased from 0.54 to 2.14 $\mu \mathrm{mol} / \mathrm{mg}$ protein, and the ergosterol content increased to 2.42 -fold to maintain membrane stability. Analysis of cell membrane fluidity and fatty acid composition showed that cell membrane fluidity decreased and unsaturated fatty acid proportions increased, leading to a $101.21 \%$ rise in the unsaturated/saturated fatty acid ratio. The results presented in this study offer guidance in understanding the salt tolerance mechanism of Z. rouxii, and in developing new strategies to increase the industrial utilization of this species under salt stress.

Keywords: Salt stress, Zygosaccharomyces rouxii, cell membrane, structure, functionality

\section{Introduction}

During the production of fermented foods, microorganisms encounter various stress conditions, and salt stress is one of the main challenges for their survival. In a hyperosmotic environment, microorganisms develop several strategies to overcome salt stress, including regulation of cellular metabolism, accumulation of compatible compounds, and activation of transporters [1].

The cell membrane is considered to be the first barrier that separates a cell from its environment and is the primary target for damage induced by environmental stress [2]. To resist salt stress, several alterations in the structure and functionality of the cell membrane have been observed, mainly including cell membrane integrity, $\mathrm{Na}^{+} / \mathrm{K}^{+}$ATPase activity, fluidity, and unsaturated fatty acid (UFA) proportion, etc. Cell integrity plays a significant role in maintaining cell viability and metabolic functions under environmental stress. In general, maintaining the integrity of cell membrane could prevent cell death at the onset of salt stress [3]. $\mathrm{Na}^{+} / \mathrm{K}^{+}$-ATPase, a protein embedded in the lipid bilayer of the cytoplasmic membrane, catalyzes ATP hydrolysis to provide energy, drives $\mathrm{Na}^{+}$and $\mathrm{K}^{+}$between both sides of cell membranes, and maintains cell osmotic pressure to provide energy for nutritive absorption [4]. Alterations in cell membrane fluidity may be related to salt tolerance. Previous research has demonstrated that high cell membrane fluidity and a homogeneous distribution of fluidity values appeared to be positively related to freezethaw resistance [5]. Regarding ethanol stress, Ishmayana et al. [6] have suggested that lower membrane fluidity led to higher ethanol tolerance. In addition, salt tolerance is reported to be closely related to the membrane lipid compositions; Turk et al. [7] revealed that salt stress causes an increase in fatty acid unsaturation in the halophilic Hortaea werneckii and halotolerant Aureobasidum pulluans. Furthermore, Sara et al. [8] found that supplemented oleic acid and ergosterol would mitigate oxidative stress in wine 
strains of Saccharomyces cerevisiae.

Zygosaccharomyces rouxii exhibits high salt tolerance and is considered an important yeast in the food fermentation process [9]. The cell membrane of $Z$. rouxii plays an important role in cellular growth, metabolism, and energy transduction. However, the behavior of $Z$. rouxii in maintaining cell membrane structure and functionality to combat salt stress has not been sufficiently explored. Therefore, in this study, we performed a comprehensive analysis of the cell membrane responses of $Z$. rouxii to salt stress.

\section{Materials and Methods}

\section{Strains and Salt Stress Experiment}

Z. rouxii CGMCC 3791 was isolated from soy sauce and identified by $26 \mathrm{~s}$ rDNA sequencing analysis. Inocula were transferred from $-80^{\circ} \mathrm{C}$ frozen stock to YPD medium $(1 \%$ yeast extract, $2 \%$ peptone and $2 \%$ glucose, $\mathrm{pH} 6.0$ ), and then incubated statically at $30^{\circ} \mathrm{C}$ for $24 \mathrm{~h}$ as pre-cultures. To investigate the growth performance of $Z$. rouxii, the pre-culture was incubated with an inoculum size of $5 \%(\mathrm{vol} / \mathrm{vol})$ to $100 \mathrm{ml}$ of YPD medium with different $\mathrm{NaCl}$ concentrations $(0 \%, 6 \%, 12 \%$, and $18 \%$ ) and cultured at $30^{\circ} \mathrm{C}$. Cells grown to the mid-exponential growth phase in different salt $(\mathrm{NaCl})$ concentrations were harvested, centrifuged at $10,000 \mathrm{~g}$ for $5 \mathrm{~min}$, and washed twice serially with saline water for subsequent analyses.

\section{Transmission Electron Microscopy (TEM) Analysis}

Samples for TEM analysis were prepared by slightly modifying the method described by $\mathrm{Wu}$ et al. [10]. The differences included that samples were fixed in $2.5 \%(\mathrm{v} / \mathrm{v})$ glutaraldehyde for $3 \mathrm{~h}$ and the cell pellets were mixed with $1 \%(\mathrm{w} / \mathrm{v})$ water agar. Epon 812 (SPI Supplies, USA), comprising cell agar slices, was sliced into 80-nm sections by using a Leica EM UC7 ultramicrotome (Leica Microsystems, Austria). These thinly sliced sections were stained with uranyl acetate and then lead citrate prior to examination under a JEM 2100 Plus electron microscope (JEOL, Japan).

\section{Determination of Intracellular $\mathrm{Na}^{+}$and $\mathrm{K}^{+}$Concentrations}

Intracellular $\mathrm{Na}^{+}$and $\mathrm{K}^{+}$concentrations were determined according to the method described by González-Hernández et al. [11]. The cells were disrupted by incubation with $200 \mu \mathrm{M}$ cetyltrimethylammonium bromide for $15 \mathrm{~min}$ at room temperature and the suspension was then centrifuged to obtain the samples. The samples were analyzed by flame atomic absorption spectroscopy (SpectrAA-220FS, VARIAN, USA).

\section{Analysis of $\mathrm{Na}^{+} / \mathrm{K}^{+}$-ATPase Activity}

$\mathrm{Na}^{+} / \mathrm{K}^{+}$-ATPase activity was evaluated by measuring the release of inorganic phosphate (Pi) from ATP according to the kit protocol (Nanjing Jiancheng Bioengineering Institute, China).
Briefly, the bacterial suspensions were sonicated on ice $(20 \mathrm{kHz}$, $25 \mathrm{~min}$ ) and centrifuged at $10,000 \mathrm{~g}$ for $5 \mathrm{~min}$ to obtain the supernatant. The $\mathrm{Na}^{+} / \mathrm{K}^{+}$-ATPase activity of the supernatant was determined by measuring the amount of $\mathrm{Pi}$ using the malachite green dye method and expressed as units per milligram of protein [12]. Protein concentration was determined according to the Bradford method by using bovine serum albumin as the standard protein.

\section{Determination of Ergosterol Concentration}

Ergosterol concentration was measured according to the method described by Alizadeh et al. [13]. Each cell mass was added to $3 \mathrm{ml}$ of ethanol solution comprising $25 \%$ potassium hydroxide and was then incubated at $85^{\circ} \mathrm{C}$ for $1 \mathrm{~h}$ in a water bath. Subsequently, a mixture of $1 \mathrm{ml}$ of sterile distilled water and $3 \mathrm{ml}$ of n-heptane (Sigma-Aldrich, USA) were added, and the solution was vortexed for $3 \mathrm{~min}$. The supernatant was obtained, and its absorbance was read at 282 and $230 \mathrm{~nm}$ using a spectrophotometer. A calibration curve was generated for standard ergosterol to calculate the ergosterol concentration, which was expressed as dry cell weight (DCW).

\section{Measurement of Cell Membrane Fluidity}

Cell membrane fluidity was determined by fluorescence anisotropy, which was performed to study the rotational diffusion of fatty acyl chains in the membrane interior, according to the method described by Liao et al. [14]. The lipid-soluble fluorescent probe 1,6-diphenyl-1,3,5-hexatriene (DPH) was used to monitor the changes in membrane dynamics. Measurements were obtained using a spectrofluorometer (model 5J1-0042, Hitachi F-7100, Japan), with excitation at $360 \mathrm{~nm}$ and emission at $430 \mathrm{~nm}$ (5-nm slits, respectively). The calculation of fluorescence anisotropy referred to the method of Ansari et al. [15]. The degree of fluorescence polarization $(p)$ and anisotropy $(r)$ were calculated as follows:

$$
p=\frac{I \mathrm{VV}-I \mathrm{VH}(I \mathrm{HV} / I \mathrm{HH})}{I \mathrm{VV}+I \mathrm{VH}(I \mathrm{HV} / I \mathrm{HH})}, \quad r=\frac{2 p}{3-p}
$$

where $I v$ is the corrected fluorescence and the subscripts $V$ and $H$ represent the values obtained by the excitation and analyzer polarizers in the vertical and horizontal direction, respectively.

\section{Extraction and Analysis of Cell Membrane Fatty Acids}

The extraction of membrane lipids and preparation of fatty acid methyl esters (FAMEs) were conducted according to the method described by Wu et al. [16]. The samples were analyzed using gas chromatography mass spectroscopy (GC-MS, Trace GC UltraDSQII, Thermo Electron Corporation, USA) according to a previously described method [17]. The relative amount of FAMEs was calculated from peak areas. The degree of unsaturation (unsaturated fatty acids/saturated fatty acids, U/S ratio) and the mean chain length were determined according to the previously described method [10]. All experiments were performed in triplicate. 


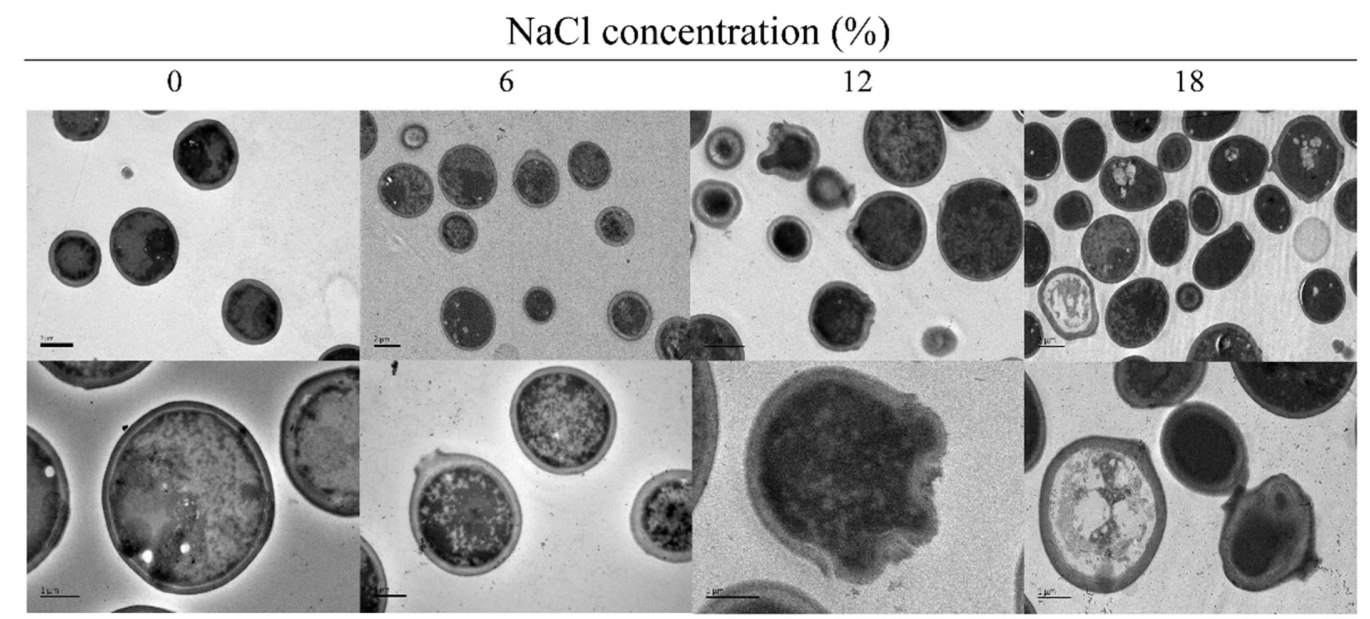

Fig. 1. TEM analyses of the morphological changes in Z. rouxii growing to mid-exponential growth phase under salt stress (NaCl concentration: $0 \%, 6 \%, 12 \%$, and $18 \%$ ).

\section{Statistical Analysis}

One-way ANOVA with Duncan's test was used to investigate the statistical differences. Differences between groups with $p$ values less than $0.05(n=3)$, were considered to be statistically significant. One-way ANOVA was performed using the SPSS software (version 19.0, SPSS Inc., IBM, USA).

\section{Results}

\section{TEM Analyses of Z. rouxii under Salt Stress}

Salt-induced changes in the cell morphology of $Z$. rouxii were revealed by TEM analysis (Fig. 1). In the absence of $\mathrm{NaCl}$, the cells were round, cell surface was smooth and cell walls were intact. Under salt stress, the cells transformed into an elliptical shape, and developed a rough surface, while the cell walls became relatively thinner and coarser. In addition, cell rupture was accompanied by intracellular substance spillover. These results showed that an increase in $\mathrm{NaCl}$ concentrations, affected $Z$. rouxii cells, including their cell shape, cell wall, cell membrane, and intracellular solute substances.

\section{Analysis of Intracellular $\mathrm{Na}^{+}$and $\mathrm{K}^{+}$Concentrations}

Changes in the intracellular metal ion $\mathrm{Na}^{+}$and $\mathrm{K}^{+}$ concentrations in $Z$. rouxii under salt stress were investigated (Fig. 2A). The results showed that with an increase in $\mathrm{NaCl}$ concentrations, intracellular $\mathrm{Na}^{+}$ concentrations increased gradually, from $0 \% \mathrm{NaCl}$ concentration (at $5.57 \pm 0.19 \mu \mathrm{g} / \mathrm{mg} \mathrm{DCW}$ ) to $18 \% \mathrm{NaCl}$ concentration (at $9.11 \pm 0.69 \mu \mathrm{g} / \mathrm{mg} \mathrm{DCW}$ ), whereas intracellular $\mathrm{K}^{+}$concentration decreased from $36.94 \pm 2.10$ to $8.68 \pm 2.86 \mu \mathrm{g} / \mathrm{mg} \mathrm{DCW}$. Meanwhile, the $\mathrm{Na}^{+} / \mathrm{K}^{+}$ratio
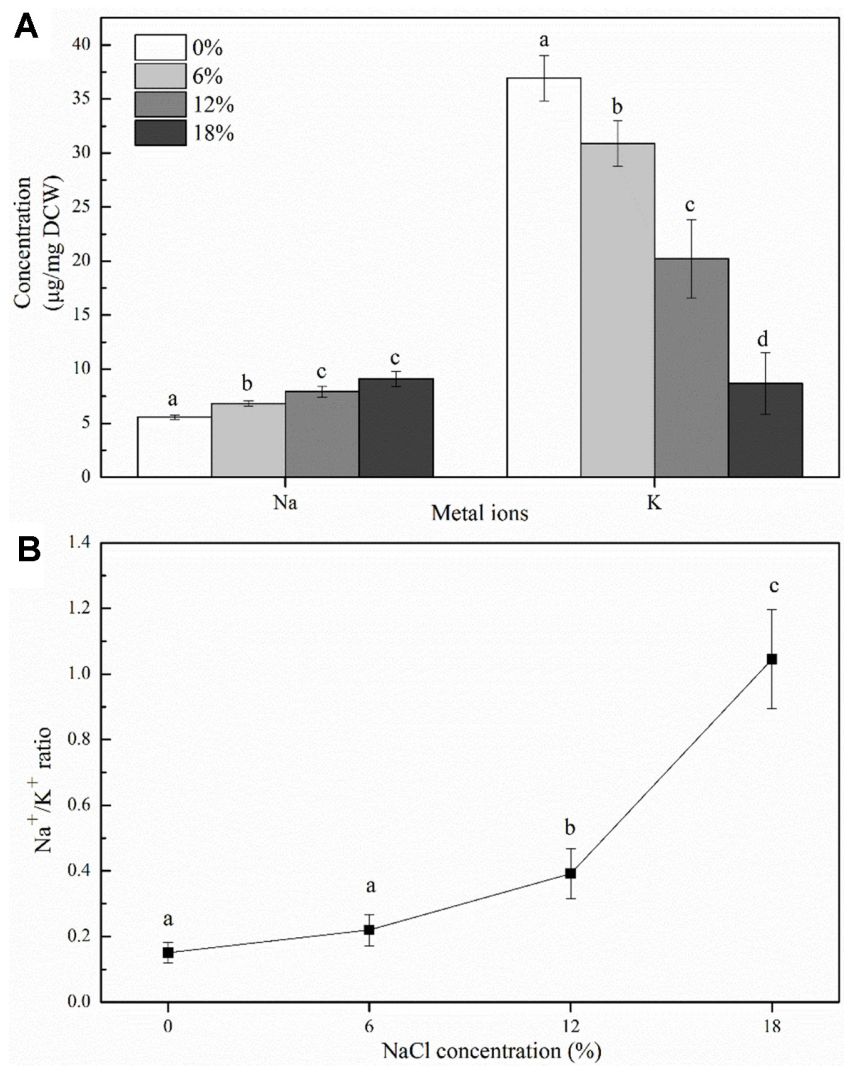

Fig. 2. Changes of intracellular $\mathrm{Na}^{+}, \mathrm{K}^{+}$concentrations (A) and $\mathrm{Na}^{+} / \mathrm{K}^{+}$ratio $($B) of $Z$. rouxii upon salt stress.

Cells were cultured to mid-exponential growth phase under salt stress ( $\mathrm{NaCl}$ concentration: $0 \%, 6 \%, 12 \%$, and $18 \%$ ) in YPD medium. Error bars: SD $(n=3)$. Statistically significant differences $(p<0.05)$ were determined by one-way ANOVA with Duncan's test and were indicated with different letters. 


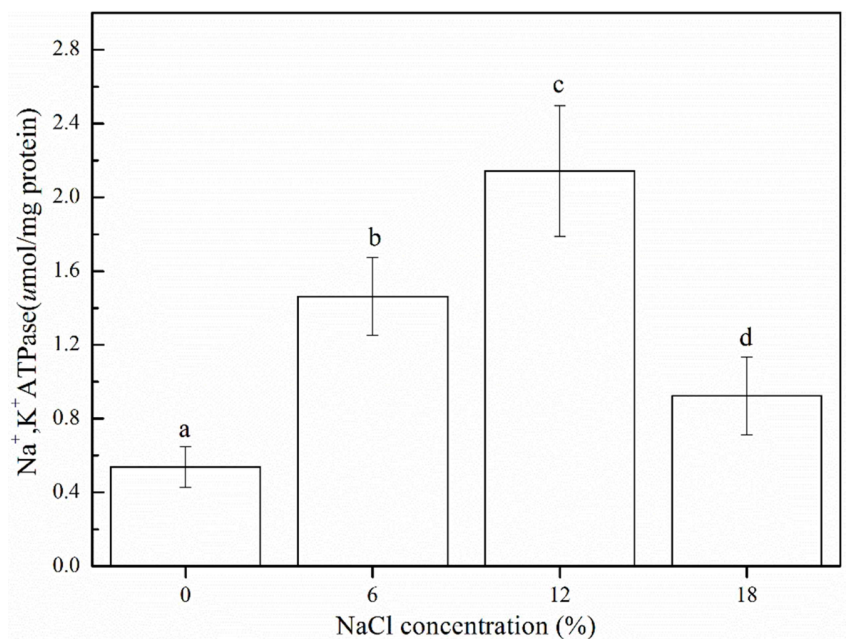

Fig. 3. Changes in $\mathrm{Na}^{+}-\mathrm{K}^{+}$-ATPase activity expression of Z. rouxii under salt stress ( $\mathrm{NaCl}$ concentration: $0 \%, 6 \%, 12 \%$, and $18 \%$ ).

Error bars: SD $(n=3)$. Statistically significant differences $(p<0.05)$ were determined by one-way ANOVA with Duncan's test and were indicated with different letters.

exhibited an increase tendency (Fig. 2B). These results suggested that salt stress caused an increase in intracellular content of $\mathrm{Na}^{+}$, and a decrease in content of $\mathrm{K}^{+}$, thus eventually resulting in an increase in the $\mathrm{Na}^{+} / \mathrm{K}^{+}$ratio.

\section{Changes in the $\mathrm{Na}^{+} / \mathrm{K}^{+}$-ATPase Activity of $Z$. rouxii under Salt Stress}

The results of $\mathrm{Na}^{+} / \mathrm{K}^{+}$-ATPase activity are presented in Fig. 3. In normal YPD medium (non-salt medium), the $\mathrm{Na}^{+} / \mathrm{K}^{+}$-ATPase activity of $Z$. rouxii was low, at $0.54 \pm$ $0.11 \mu \mathrm{mol} / \mathrm{mg}$ protein. With increasing $\mathrm{NaCl}$ concentrations, $\mathrm{Na}^{+} / \mathrm{K}^{+}$-ATPase activity increased gradually, and the maximum activity $(2.14 \pm 0.35 \mu \mathrm{mol} / \mathrm{mg}$ protein $)$ was obtained under $12 \% \mathrm{NaCl}$ concentration. $\mathrm{Na}^{+} / \mathrm{K}^{+}$-ATPase activity decreased to $0.93 \pm 0.21 \mu \mathrm{mol} / \mathrm{mg}$ protein when the $\mathrm{NaCl}$ concentration was further increased to $18 \%$. These results showed that an increase in $\mathrm{Na}^{+} / \mathrm{K}^{+}$-ATPase activity is a common strategy used by $Z$. rouxii to counteract salt stress.

\section{Accumulation of Ergosterol in Z. rouxii under Salt Stress}

Ergosterol concentrations in Z. rouxii under different salt stress $(\mathrm{NaCl})$ conditions are presented in Fig. 4. These concentrations increased with an increase in $\mathrm{NaCl}$ concentration, and the maximum accumulation of ergosterol $(195.96 \pm 8.96 \mathrm{mg} / \mathrm{g} \mathrm{DCW})$ was obtained at $18 \% \mathrm{NaCl}$. A 2.42 -fold higher concentration was observed at $18 \% \mathrm{NaCl}$,

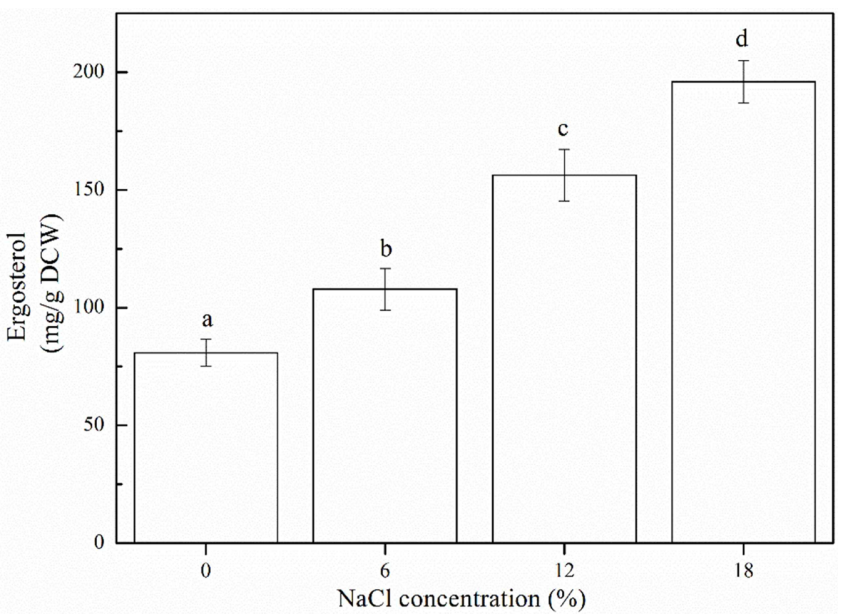

Fig. 4. Accumulation of ergosterol by Z. rouxii in response to salt stress ( $\mathrm{NaCl}$ concentration: $0 \%, 6 \%, 12 \%$, and $18 \%$ ).

Error bars: SD $(n=3)$. Statistically significant differences $(p<0.05)$ were determined by one-way ANOVA with Duncan's test and were indicated with different letters.

than that observed in the absence of $\mathrm{NaCl}$, thus suggesting that accumulation of ergosterol is a common response under salt stress.

\section{Changes in Cell Membrane Fluidity in Z. rouxii under Salt Stress}

DPH is considered to be a sensitive fluorescent probe for studying the fluidity of membrane lipids because it can bind to their non-polar hydrocarbon chain. Fig. 5 presents the changes in cell membrane fluidity under salt stress. A significant increase in fluorescence anisotropy from 0.28 to 0.32 occurred when $\mathrm{NaCl}$ concentrations were increased from $0 \%$ to $18 \%$. Meanwhile, the polarization also increased gradually from 0.20 to 0.24 , and reached its maximum at $18 \% \mathrm{NaCl}$ concentration. Generally, an increase in fluorescence anisotropy reflects a decrease in the fluidity of the lipid bilayer. Taken together, these results revealed that an increase in salt stress caused a decrease in cell membrane fluidity in Z. rouxii, and that this strategy protects cells from salt stress.

\section{Regulation of Membrane Fatty Acid Composition in Z. rouxii under Salt Stress}

The fatty acids in cell membranes play an important role in maintaining membrane integrity and regulating the activity of membrane proteins. The effect of salt stress on cell membrane fatty acid composition is shown in Fig. 6: a total of 7 fatty acids, including 4 saturated fatty acids 

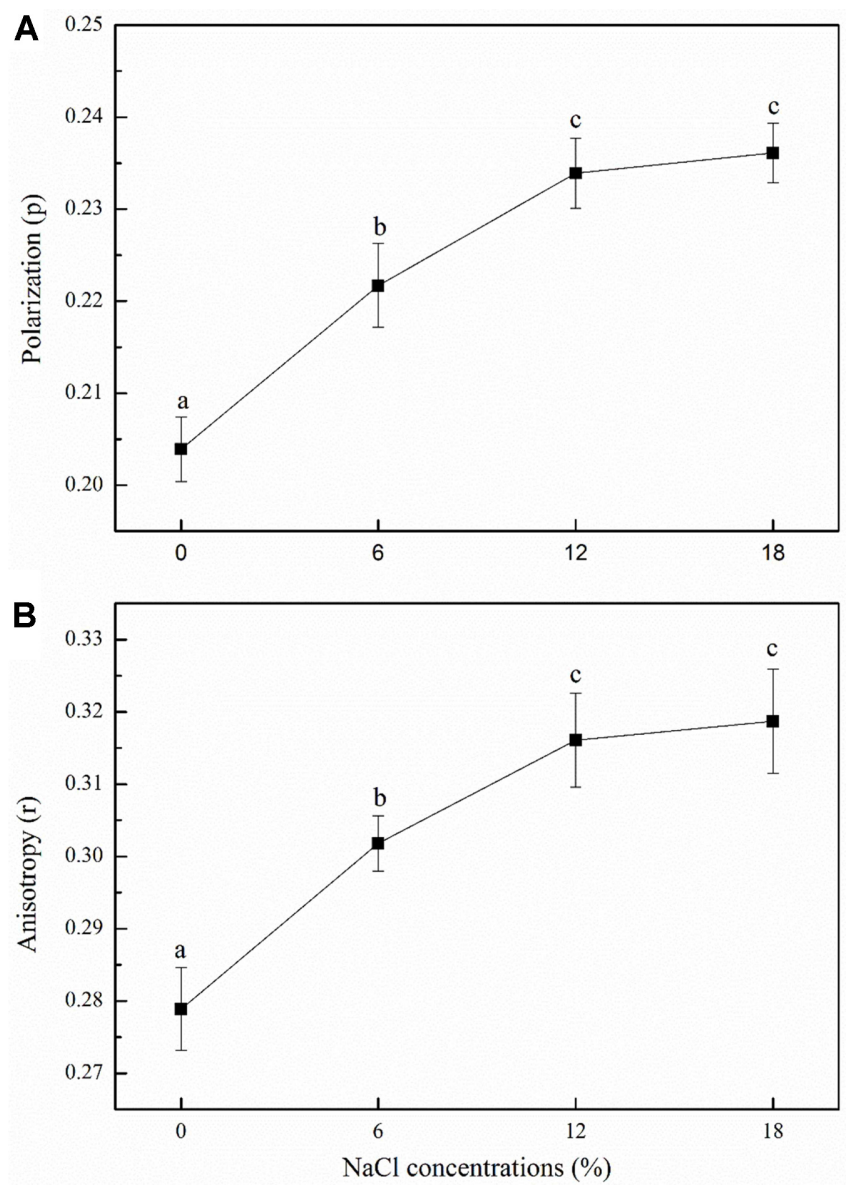

Fig. 5. Changes in membrane fluidity of Z. rouxii under salt stress ( $\mathrm{NaCl}$ concentration: $0 \%, 6 \%, 12 \%$, and $18 \%$ ).

The degree of fluorescence polarization (A) and anisotropy (B) changes were measured by the spectrofluorometer. Error bars: SD $(n=3)$. Statistically significant differences $(p<0.05)$ were determined by one-way ANOVA with Duncan's test and were indicated with different letters.

(lauric C12:0, myristic C14:0, palmitic C16:0, and stearic C18:0) and 3 unsaturated fatty acids (palmitoleic C16:1, oleic $\mathrm{C} 18: 1$, linoleic $\mathrm{C} 18: 2$ ), exhibited significant changes in their relative contents. In the absence of $\mathrm{NaCl}$, the major cell membrane fatty acids of $Z$. rouxii were palmitic acid (C16:0), oleic acid (C18:1 n-9), and hexadecenoic acid (C16:1 n-7), which accounted for approximately $78 \%$ of the total fatty acid content. The contents of all saturated fatty acids (C14:0, C16:0, and C18:0, except C12:0) decreased with the increase in $\mathrm{NaCl}$ concentrations. In the case of unsaturated fatty acids, the proportions of hexadecenoic acid (C16:1 n-7) and oleic acid (C18:1 n-9) increased, whereas that of linoleic acid (C18:2) decreased. In addition, the $U / S$ ratio and mean chain length were determined
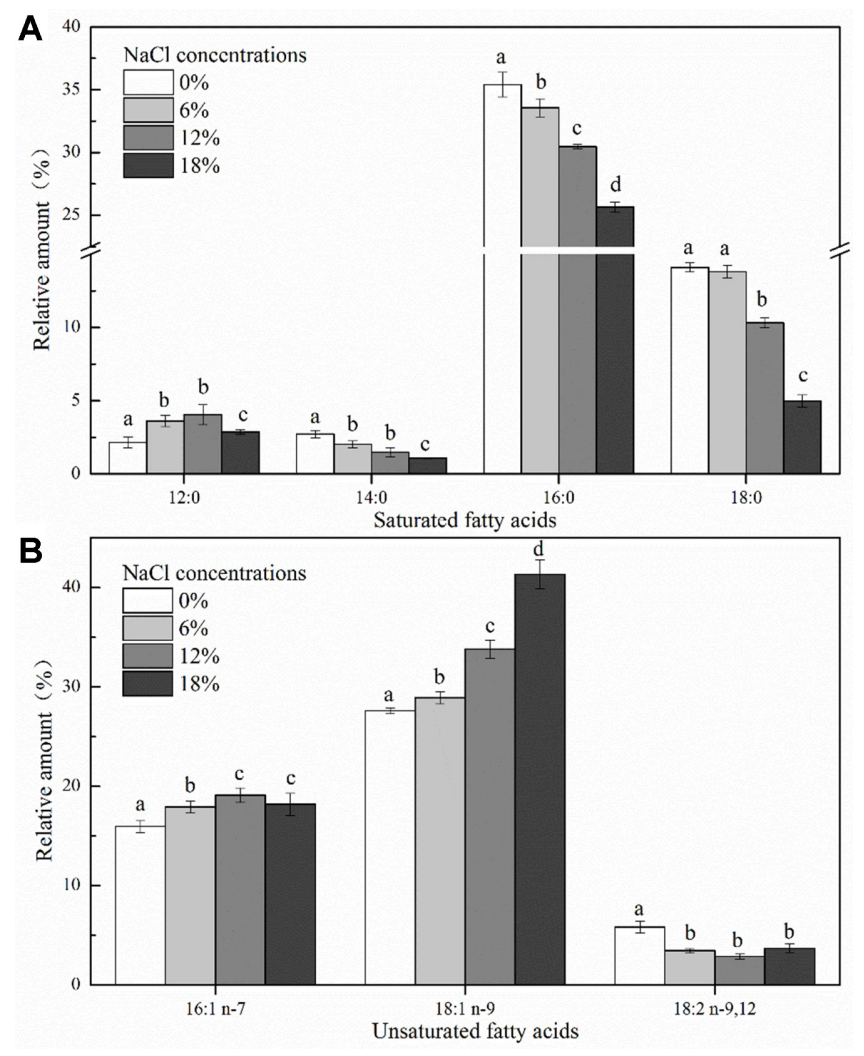

Fig. 6. Alterations in membrane fatty acid proportions of Z. rouxii under salt stress ( $\mathrm{NaCl}$ concentration: $0 \%, 6 \%, 12 \%$, and $18 \%)$.

Cells were cultured to mid-exponential growth phase under salt stress, and the proportion of membrane fatty acids including saturated fatty acids (A) and unsaturated fatty acids (B) were determined by GC-MS. The relative amount of FAMEs was calculated from peak areas. Error bars: SD $(n=3)$. Statistically significant differences $(p<0.05)$ were determined by one-way ANOVA with Duncan's test and were indicated with different letters.

during salt stress (Fig. 7). With the $\mathrm{NaCl}$ concentration increasing to $18 \%$, the U/S ratio increased by $101.21 \%$ and the mean chain length decreased by $5.16 \%$ compared with that observed in the absence of salts. It can be seen that the proportion of unsaturated fatty acids increased under salt stress, thereby resulting in a significant increase in U/S ratio.

\section{Discussion}

In present study, we performed a comprehensive analysis of the cell membrane structure and functionally in Z. rouxii to elucidate its response to salt stress. TEM analysis revealed that under salt stress, the shape of 

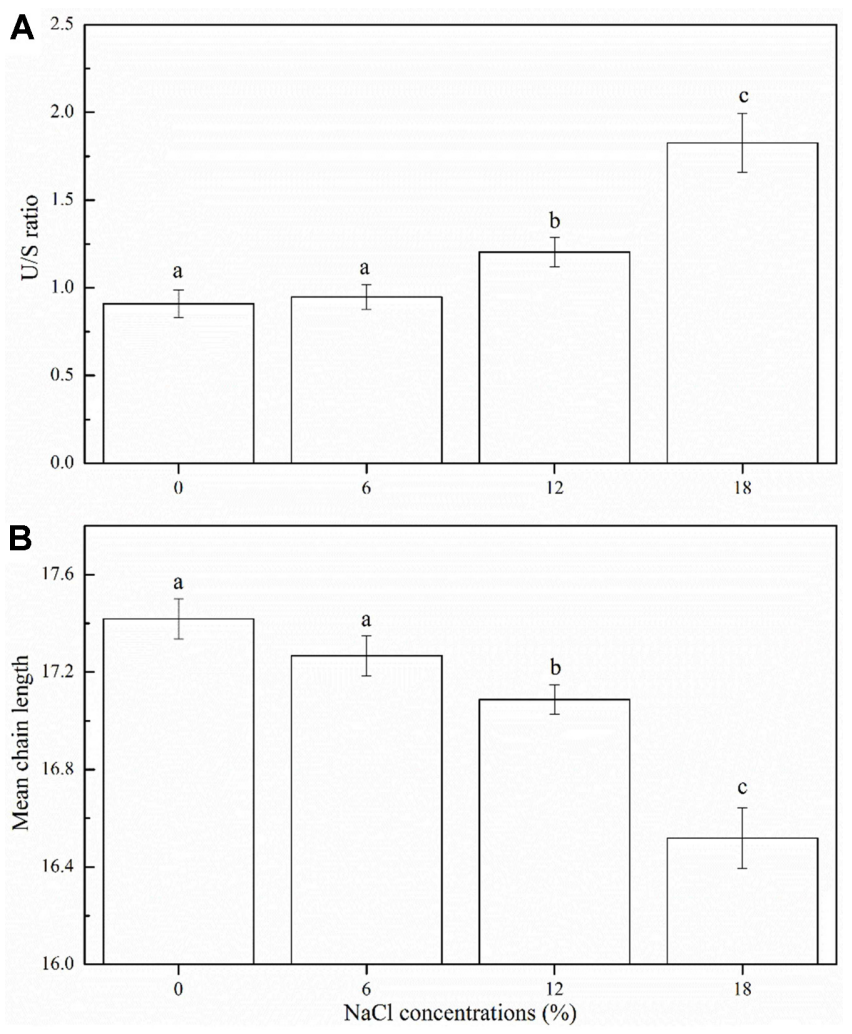

Fig. 7. The unsaturation degree (A) and mean chain length (B) changes in membrane fatty acids of $Z$. rouxii under salt stress ( $\mathrm{NaCl}$ concentration: $0 \%, 6 \%, 12 \%$ and $18 \%$ ).

The degree of unsaturation was calculated by unsaturated fatty acids/saturated fatty acids (U/S ratio). Error bars: SD $(n=3)$. Statistically significant differences $(p<0.05)$ were determined by oneway ANOVA with Duncan's test and were indicated with different letters.

Z. rouxii cells changed from round to elliptical and that some cell walls were ruptured, which was accompanied by intracellular substance spillover (Fig. 1). Similarly, Gandhi et al. [18] investigated the effects of salt stress on the morphology of Lactobacillus acidophilus, Lactobacillus casei, and Bifidobacterium bifidum by TEM, and found that at $10 \%$ $\mathrm{NaCl}$ concentration, the cell structures of all the bacteria were irregular with several deformities in the cell membranes. Therefore, the change in cell structure can be considered as a mean of adaptation of the cells to unfavorable environmental conditions.

Regarding intracellular $\mathrm{Na}^{+}$and $\mathrm{K}^{+}$concentrations (Fig. 2A), it was observed that $\mathrm{Na}^{+}$concentrations increased with the increase in $\mathrm{NaCl}$ concentrations. The $\mathrm{Na}^{+} / \mathrm{K}^{+}$ratio showed an increasing trend, and under salt stress, this ratio was significantly higher than that in the absence of salts
(Fig. 2B). A similar result has been reported by Andreishcheva et al. [19], who showed that intracellular $\mathrm{Na}^{+}$concentrations have a small but reproducible increase at 9\% salt concentration. This may be explained by the fact that extracellular $\mathrm{Na}^{+}$concentrations were much higher than intracellular $\mathrm{Na}^{+}$concentrations, and $\mathrm{Na}^{+}$was forced into the cell due to this concentration gradient. Conversely, the $\mathrm{K}^{+}$concentrations decreased significantly from $36.9 \pm 2.10$ to $8.68 \pm 2.86 \mu \mathrm{g} / \mathrm{mg}$ when $\mathrm{NaCl}$ concentrations increased from $0 \%$ to $18 \%$. The significant decrease in $\mathrm{K}^{+}$content may result from $\mathrm{Na}^{+}$ions entering the cell, leading to an increase in intracellular pressure, which caused the cells to extrude $\mathrm{K}^{+}$as a way to counterbalance [20]. Generally, regulation of the intracellular $\mathrm{Na}^{+} / \mathrm{K}^{+}$ratio is a strategy to resist salt stress, and previous research has suggested that bacteria respond to hypertonic stress by $\mathrm{Na}^{+}$exclusion and $\mathrm{K}^{+}$uptake [21]. Maintaining a low $\mathrm{Na}^{+} / \mathrm{K}^{+}$ratio would help cells survive under salt stress [22]. In the present study, the $\mathrm{Na}^{+} / \mathrm{K}^{+}$ratio increased significantly at $18 \% \mathrm{NaCl}$ concentration, thus suggesting that cells were severely damaged at this salt concentration. The $\mathrm{Na}^{+} / \mathrm{K}^{+}$-ATPase is a transmembrane protein that maintains the homeostasis of cells by regulating the intracellular $\mathrm{Na}^{+}$and $\mathrm{K}^{+}$gradient [23]. Most euryhaline organisms exhibit adaptive changes in $\mathrm{Na}^{+} / \mathrm{K}^{+}$-ATPase activity following salinity changes [24]. Moreover, $\mathrm{Na}^{+} / \mathrm{K}^{+}$ATPase is a widely recognized biomarker for evaluating salinity adaptation. Petrezsélyová et al. [25] revealed that the up-regulation of the $\mathrm{Na}^{+} / \mathrm{K}^{+}$-ATPase Ena1 expression is a crucial event for adaptation to high salt stress in the budding yeast $S$. cerevisiae. In the present study, $\mathrm{Na}^{+} / \mathrm{K}^{+}$ATPase activity increased and significant differences were observed between the salinity treatments (Fig. 3). Thus, it can be inferred that $\mathrm{Na}^{+} / \mathrm{K}^{+}$-ATPase activity was increased in Z. rouxii under salt stress to create electrochemical gradients that provide the driving force for ion transport. At $18 \% \mathrm{NaCl}$ concentration, $\mathrm{Na}^{+}-\mathrm{K}^{+}$-ATPase activity decreased to $0.93 \mu \mathrm{mol} / \mathrm{mg}$ protein, which can be mutually corroborated with the considerably increasing $\mathrm{Na}^{+} / \mathrm{K}^{+}$ratio.

Ergosterol is a sterol found in lower eukaryotic cell membranes, and it plays an important role in cell membrane fluidity and permeability. It has been reported that ergosterol maintains the structural integrity of yeast membranes under stressful environmental conditions [26, 27]. Abe et al. [28] analyzed the ability of ergosterol in adjusting the dynamic properties of plasma membranes, and showed that the erg 2 mutation decreased the membrane order parameter, and drastically increased the rotational diffusion coefficient of plasma membranes, thus providing evidence for the requirement of ergosterol for membrane 
integrity. In the present study, the ergosterol concentration gradually increased with the increase in the salt $(\mathrm{NaCl})$ concentration (Fig. 4), which is consistent with the results reported in a previous study [29]. Swan et al. [30] revealed that cells with high levels of sterols were more tolerant to environmental stress, and that ergosterol concentrations were parallel to the survival data. Yu et al. [31] also found that ergosterol concentrations were 1.6-fold higher than parent strains, which enhanced the stress tolerance of $S$. cerevisiae. Therefore, it can be inferred that $Z$. rouxii increases the biosynthesis of ergosterol to maintain cell membrane stability and reduce the damage caused by salt stress. The biosynthesis of ergosterol is tightly regulated by 25 known enzymes of the ergosterol production pathway [32]. Zhang et al. [33] have revealed that the ergosterol synthesis genes in Pichia pastoris, such as ERG2, ERG3 and ERG6, upregulated under ethanol stress, indicating that unsaturated fatty acids and ergosterol act synergistically to some extent to protect the plasma membrane. Furthermore, Kamthan et al. [34] have found that an increase in ethanol concentrations and thermal tolerance in fission yeast can be attributed to a 1.5-fold increase in ergosterol and oleic acid concentrations, which are consistent with the results obtained in the present study.

Membrane fluidity, which is well known to be essential for cell function, is an important regulator of cellular responses to ambient environmental stress to maintain the biologically active state of cell membranes [35]. In the present study, changes in cell membrane fluidity were determined by the rotational diffusion of fatty acyl chains, which was determined by fluorescence anisotropy with DPH as a probe. DPH is considered to be a sensitive fluorescent probe for studying the fluidity of membrane lipids because it can be bind to the nonpolar hydrocarbon chain of membrane lipids. As expected, the findings of the present study showed that an increase in salt stress resulted in a decrease in cell membrane fluidity of $Z$. rouxii, which was consistent with the results reported in previous studies [36-38]. Murínová and Dercová [39] have revealed that in the presence of unfavorable compounds such as toxic agents, cell membrane fluidity decreases to prevent the entry of these toxic compounds into the cells. Therefore, it can be inferred that under salt stress, Z. rouxii cells decrease cell membrane fluidity to protect the cells by preventing the entry of excessive salts. In addition, the regulation of cell membrane fatty acid profiles is one of the effective methods for cells to combat environmental stress. Under high osmotic pressure, most cells maintain their biochemical function by altering the membrane components
[40]. The results of cell membrane fatty acid analysis showed that the proportion of total UFAs increased, whereas that of SFAs decreased, thereby resulting in a $101.21 \%$ increase in the U/S ratio (Fig. 7). Similar results were reported in a study on Debaryomyces hansenii under salt stress [41], which showed that high $\mathrm{NaCl}$ concentrations result in an increase in the degree of unsaturation magnitude of fatty acids within the membrane. Based on these results, the interesting relationship between cell membrane fluidity and fatty acid composition must be discussed further. The extent of cell membrane fluidity is also affected by the changes in fatty acid composition within the membrane phospholipids. The changes in the fluidity of natural membranes are related to chemical kinetics [42]. The increase in the U/S ratio and mean chain length may contribute to maintaining cell membrane fluidity, because membranes comprising long chain fatty acids are densely arranged, whereas those comprised of UFA are loosely arranged and more fluid [43]. However, the results of the present study do not seem completely consistent with this mechanism, because the proportion of UFAs in Z. rouxii increased under salt stress, whereas the cell membrane fluidity and mean chain length decreased slightly (Figs. 57). This decrease in cell membrane fluidity may also be related to high salt concentrations. Qi et al. [36] have found that the decrease in cell membrane fluidity could restrict the influx of $\mathrm{Na}^{+}$and increase $\mathrm{Na}^{+} / \mathrm{K}^{+}$-ATPase activity in response to salt stress.

In conclusion, we used a physiological approach in the present study to investigate the responses of $Z$. rouxii to salt stress at the membrane level using salt tolerance tests to reveal its protective mechanisms. The results of our study elucidate the tolerance mechanisms of $Z$. rouxii at high salt $(\mathrm{NaCl})$ concentrations, which may be useful in the development of new strategies to increase the industrial utilization of this species under salt stress.

\section{Acknowledgments}

This work was financially supported by the National Natural Science Foundation of China $(31871787,31671849)$. The authors would like to thank Zhonghui Wang (College of Light Industry, Textile and Food Engineering, Sichuan University) for her great help in GC-MS analysis.

\section{Conflict of Interest}

The authors have no financial conflicts of interest to declare. 


\section{References}

1. Bert P, Paul B, Folgering JHA, Friesen RHE, Moe PC, Tiemen VDH. 2010. How do membrane proteins sense water stress? Mol. Microbiol. 44: 889-902.

2. Zhang YM, Rock CO. 2008. Membrane lipid homeostasis in bacteria. Nat. Rev. Microbiol. 6: 222-233.

3. Hoang TML, Williams B, Khanna H, Dale J, Mundree SG. 2014. Physiological basis of salt stress tolerance in rice expressing the anti-apoptotic gene SfIAP. Funct. Plant Biol. 41: 1168-1177.

4. Gorini A, Canosi U, Devecchi E, Geroldi D, Villa RF. 2002. ATPases enzyme activities during ageing in different types of somatic and synaptic plasma membranes from rat frontal cerebral cortex. Prog. Neuropsychopharmacol. Biol. Psychinatry 26: $81-90$.

5. Meneghel J, Passot S, Cenard S, Réfrégiers M, Jamme F, Fonseca F. 2017. Subcellular membrane fluidity of Lactobacillus delbrueckii subsp. bulgaricus under cold and osmotic stress. Appl. Microbiol. Biotechnol. 101: 6907-6917.

6. Ishmayana S, Kennedy UJ, Learmonth RP. 2017. Further investigation of relationships between membrane fluidity and ethanol tolerance in Saccharomyces cerevisiae. World J. Microbiol. Biotechnol. 33: 218-228.

7. Turk M, Méjanelle L, Šentjurc M, Grimalt JO, Gundecimerman N, Plemenitaš A. 2004. Salt-induced changes in lipid composition and membrane fluidity of halophilic yeast-like melanized fungi. Extremophiles 8: 53-61.

8. Sara L, Giacomo Z, Severino Z, Marilena B, Maurizio C, Ilaria M. 2010. Oleic acid and ergosterol supplementation mitigates oxidative stress in wine strains of Saccharomyces cerevisiae. Int. J. Food. Microbiol. 141: 229-235.

9. Dakal TC, Solieri L, Giudici P. 2014. Adaptive response and tolerance to sugar and salt stress in the food yeast Zygosaccharomyces rouxii. Int. J. Food. Microbiol. 185: 140-157.

10. Wu C, Zhang J, Wang M, Du G, Chen J. 2012. Lactobacillus casei combats acid stress by maintaining cell membrane functionality. J. Ind. Microbiol. Biot. 39: 1031-1039.

11. González-Hernández JC, Jiménez-Estrada M, Peña A. 2005. Comparative analysis of trehalose production by Debaryomyces hansenii and Saccharomyces cerevisiae under saline stress. Extremophiles 9: 7-16.

12. Zhao Q, Shao L, Hu X, Wu G, Du J, Xia J, et al. 2013. Lipoxin $\mathrm{A}_{4}$ preconditioning and postconditioning protect myocardial ischemia/reperfusion injury in rats. Mediators. Inflamm. 2013: 231351.

13. Alizadeh F, Khodavandi A, Zalakian S. 2017. Quantitation of ergosterol content and gene expression profile of ERG11 gene in fluconazole-resistant Candida albicans. Curr. Med. Mycol. 3: 13-19.

14. Liao ZG, Tang T, Guan XJ, Dong W, Zhang J, Zhao GW, et al. 2016. Improvement of transmembrane transport mechanism study of imperatorin on P-glycoprotein-mediated drug transport. Molecules. 21: e1606.

15. Ansari S, Gupta P, Mahanty SK, Prasad R. 1993. The uptake of amino acids by erg mutants of Candida albicans. J. Med. Vet. Mycol. 31: 377-386.

16. Wu C, Zhang J, Chen W, Wang M, Du G, Chen J. 2012. A combined physiological and proteomic approach to reveal lactic-acid-induced alterations in Lactobacillus casei Zhang and its mutant with enhanced lactic acid tolerance. Appl. Microbioliol. Biotechnol. 93: 707-722.

17. Zheng J, Liang R, Zhang L, Wu C, Zhou R, Liao X. 2013. Characterization of microbial communities in strong aromatic liquor fermentation pit muds of different ages assessed by combined DGGE and PLFA analyses. Food Res. Int. 54: 660666.

18. Gandhi A, Shah NP. 2016. Effect of salt stress on morphology and membrane composition of Lactobacillus acidophilus, Lactobacillus casei, and Bifidobacterium bifidum, and their adhesion to human intestinal epithelial-like Caco-2 cells. J. Diary. Sci. 99: 2594-2605.

19. Andreishcheva EN, Isakova EP, Sidorov NN, Abramova NB, Ushakova NA, Shaposhnikov GL, et al. 1999. Adaptation to salt stress in a salt-tolerant strain of the yeast Yarrowia lipolytica. Biochemistry (Moscow) 64: 1061-1067.

20. Sunder S, Singh AJ, Gill S, Singh B. 1996. Regulation of intracellular level of $\mathrm{Na}^{+}, \mathrm{K}^{+}$and glycerol in Saccharomyces cerevisiae under osmotic stress. Mol. Cell. Biochem. 158: 121124.

21. Fu X, Liang W, Du P, Yan M, Kan B. 2014. Transcript changes in Vibrio cholerae in response to salt stress. Gut Pathog. 6: 47.

22. Sanadhya P, Agarwal P, Khedia J, Agarwal PK. 2015. A low-affinity $\mathrm{K}^{+}$transporter AlHKT2;1 from recretohalophyte Aeluropus lagopoides confers salt tolerance in Yeast. Mol. Biotechnol. 57: 489-498.

23. Yin W, Li X, Feng S, Cheng W, Tang B, Shi YL, et al. 2009. Plasma membrane depolarization and $\mathrm{Na}, \mathrm{K}$-ATPase impairment induced by mitochondrial toxins augment leukemia cell apoptosis via a novel mitochondrial amplification mechanism. Biochem. Pharmacol. 78: 191-202.

24. Li J, Wang J, Yang L, Chen Y, Zhou Y. 2014. Changes in plasma osmolality and $\mathrm{Na}^{+} / \mathrm{K}^{+}$ATPase activity of juvenile obscure puffer Takifugu obscurus following salinity challenge. Biochem. Syst. Ecol. 56: 111-117.

25. Petrezsélyová S, López-Malo M, Canadell D, Roque A, Serra-Cardona A, Marqués MC, et al. 2016. Regulation of the $\mathrm{Na}^{+} / \mathrm{K}^{+}$-ATPase Ena1 expression by calcineurin/Crz1 under high pH stress: a quantitative study. PLoS One 11: e0158424.

26. Dickey AN, Wen-Sau Y, Wen-Saul Y, Roland F. 2009. Using ergosterol to mitigate the deleterious effects of ethanol on bilayer structure. J. Phys. Chem. B. 113: 2388-2397.

27. Villares A, Mateo-Vivaracho L, García-Lafuente A, Guillamón E. 2014. Storage temperature and UV-irradiation influence 
on the ergosterol content in edible mushrooms. Food Chem. 147: 252-256.

28. Abe F, Hiraki T. 2009. Mechanistic role of ergosterol in membrane rigidity and cycloheximide resistance in Saccharomyces cerevisiae. BBA-Biomembranes 1788: 743-752.

29. Montañés FM, Pascual-Ahuir A, Proft M. 2011. Repression of ergosterol biosynthesis is essential for stress resistance and is mediated by the Hog1 MAPK kinase and the Mot3 and Rox1 transcription factors. Mol. Microbiol. 79: 1008-1023.

30. Swan TM, Watson K. 2010. Stress tolerance in a yeast sterol auxotroph: role of ergosterol, heat shock proteins and trehalose. FEMS Microbiol. Lett. 169: 191-197.

31. Yu KO, Ju J, Ramzi AB, Choe SH, Kim SW, Park C, et al. 2012. Increased ethanol production from glycerol by Saccharomyces cerevisiae strains with enhanced stress tolerance from the overexpression of SAGA complex components. Enzyme Microb. Technol. 51: 237-243.

32. Bhattacharya S, Esquivel BD, White TC. 2018. Overexpression or deletion of ergosterol biosynthesis genes alters doubling time, response to stress agents, and drug susceptibility in Saccharomyces cerevisiae. mBio 9: e1291-18.

33. Zhang M, Yu Q, Liang C, Zhang B, Li M. 2016. Lipid homeostasis is involved in plasma membrane and endoplasmic reticulum stress in Pichia pastoris. Biochem. Bioph. Res. Co. 478: 777-783.

34. Kamthan A, Kamthan M, Datta A. 2017. Expression of C-5 sterol desaturase from an edible mushroom in fisson yeast enhances its ethanol and thermotolerance. PLoS One 12: $\mathrm{e} 0173381$.

35. Los DA, Allakhverdiev SI. 2013. Regulatory role of membrane fluidity in gene expression and physiological functions. Photosynth. Res. 116: 489-509.
36. Qi W, Fan ZC, Wang CL, Hou LH, Wang XH, Liu JF, et al. 2014. Comparative study of physiological adaptation to salt stress in the genome shuffled Candida versatilis and a wildtype salt-tolerant yeast strain. Eur. Food. Res. Technol. 238: 675-682.

37. Chen GQ, Yue, Chen F. 2010. Salt-induced alterations in lipid composition of diatom Nitzschia laevis (Bacillariophycease) under heterotrophic culture condition. J. Phycol. 44: 13091314.

38. Kerkeb L, Donaire JP, Venema K, RodrãGuez-Rosales MP. 2010. Tolerance to $\mathrm{NaCl}$ induces changes in plasma membrane lipid composition, fluidity and $\mathrm{H}^{+}$-ATPase activity of tomato calli. Physiol. Plant. 113: 217-224.

39. MurãNovã S, Dercovã K. 2014. Response mechanisms of bacterial degraders to environmental contaminants on the level of cell walls and cytoplasmic membrane. Int. J. Food Microbiol. 2014: 1-16.

40. Cholewa JM, Lucas GEF, Nelo Eidy Z. 2014. Effects of betaine on performance and body composition: a review of recent findings and potential mechanisms. Amino Acids. 46: 1785-1793.

41. Turk M, Montiel V, Zigon D, Plemenitas A, Ramos J. 2007. Plasma membrane composition of Debaryomyces hansenii adapts to changes in $\mathrm{pH}$ and external salinity. Microbiology 153: 3586-3592.

42. Beney L, Gervais P. 2001. Influence of the fluidity of the membrane on the response of microorganisms to environmental stresses. Appl. Microbiol. Biotechnol. 57: 34-42.

43. Moorman MA, Thelemann CA, Zhou S, Pestka JJ, Linz JE, Ryser ET. 2008. Altered hydrophobicity and membrane composition in stress-adapted Listeria innocua. J. Food Prot. 71: 182-185. 